\title{
Influence of Sn Doping on Phase Transformation and Crystallite Growth of $\mathrm{TiO}_{2}$ Nanocrystals
}

\author{
Guozhu Fu, ${ }^{1}$ Yanqiu Yang, ${ }^{2}$ Gang Wei, ${ }^{1}$ Xin Shu, ${ }^{1}$ Ning Qiao, ${ }^{1}$ and Li Deng ${ }^{2,3}$ \\ ${ }^{1}$ State Key Laboratory of Chemical Resource Engineering, Beijing University of Chemical Technology, Beijing 100029, China \\ ${ }^{2}$ Beijing Bioprocess Key Laboratory, Beijing University of Chemical Technology, Beijing 100029, China \\ ${ }^{3}$ Amoy-BUCT Industrial of Biotechnovation Institute, Amoy 361026, China
}

Correspondence should be addressed to Li Deng; dengli@mail.buct.edu.cn

Received 16 January 2014; Accepted 2 February 2014; Published 10 March 2014

Academic Editor: Shao-Wen Cao

Copyright @ 2014 Guozhu Fu et al. This is an open access article distributed under the Creative Commons Attribution License, which permits unrestricted use, distribution, and reproduction in any medium, provided the original work is properly cited.

Sn doped $\mathrm{TiO}_{2}$ nanocrystals were synthesized via a single-step hydrothermal method and the influences of $\mathrm{Sn}$ doping on $\mathrm{TiO}_{2}$ have been investigated. It is found that Sn doping not only facilitates the crystal transfer from anatase to rutile but also facilitates the morphology change from sphere to rod. The states of Sn were studied by XPS and the creation of oxygen vacancies by Sn doping is confirmed. Moreover, the HRTEM results suggest that Sn facilitates preferential growth of resulting nanocrystals along (110) axis, which results in the formation of rod-like rutile nanocrystals.

\section{Introduction}

In recent years, the applications of semiconductors in photocatalysis and other fields have attracted much interest $[1,2]$, and many semiconductor nanomaterials and their heterogeneous structures have been developed for their application in energy and environmental applications [3-5], for example, the investigations of $\mathrm{TiO}_{2}$ on various organic pollutants photodegradation [6] due to its excellent photocatalytic activity, physical and chemical stability, and nontoxicity [7]. Because most of the solar energy is focused on the visible light, it is important to develop the visible-light-driven photocatalysts. However, $\mathrm{TiO}_{2}$ is only sensitive to UV light because of its large band gap $(3.2 \mathrm{eV})$. In order to efficiently use solar energy, many methods have been studied. An effective way is to introduce foreign ions into $\mathrm{TiO}_{2}$, including rare earth element doping [8], metals doping [9], and nonmetals doping $[10,11]$.

The property of $\mathrm{TiO}_{2}$ can also be affected by foreign metal ions doping. It has been shown that the photocatalytic activity of the modified $\mathrm{TiO}_{2}$ improves to different extents depending on different ion doping, such as $\mathrm{Mn}^{2+}$ [12], $\mathrm{Zr}^{4+}$ [13], and $\mathrm{Fe}^{3+}[14]$. Moreover, the phase transformation behavior and structure of $\mathrm{TiO}_{2}$ are also affected by foreign metal ions. For example, $\mathrm{Ag}^{+}[15], \mathrm{Mn}^{2+}$ [16], and $\mathrm{Cr}^{3+}$ [17] are proved to promote phase transformation from anatase to rutile, while silicon ion doping strongly restrains the phase transformation [18] and lowers the phase transition temperature [19]. But, so far, no detailed study has been reported on the influence of $\mathrm{Sn}^{4+}$ doping on the phase transformation and structure of hydrothermal synthesis $\mathrm{TiO}_{2}$.

In our work, $\mathrm{Sn}$ doped $\mathrm{TiO}_{2}$ nanocrystals were prepared by hydrothermal method. The existing states of $\mathrm{Sn}$ and its role in phase transformation as well as the morphology evolution were investigated. Sn facilitates the phase conversion from anatase to rutile and prefers the morphology evolution from spherical shape to nanorods.

\section{Experimental Section}

Sn doped $\mathrm{TiO}_{2}$ nanoparticles were prepared by hydrothermal method. $2.9 \mathrm{~mL}$ acetic acid was added to $17 \mathrm{~mL}$ tetrabutyl titanate and stirred for $15 \mathrm{~min}$. The mixture was then poured into $73 \mathrm{~mL}$ of water and vigorously stirred for 1 hour. After adding $1 \mathrm{~mL}$ concentrated nitric acid, the mixture was heated to $80^{\circ} \mathrm{C}$ and peptized for $75 \mathrm{~min}$. Then the volume was adjusted with water to $80 \mathrm{~mL}$. The mixture was kept in a 


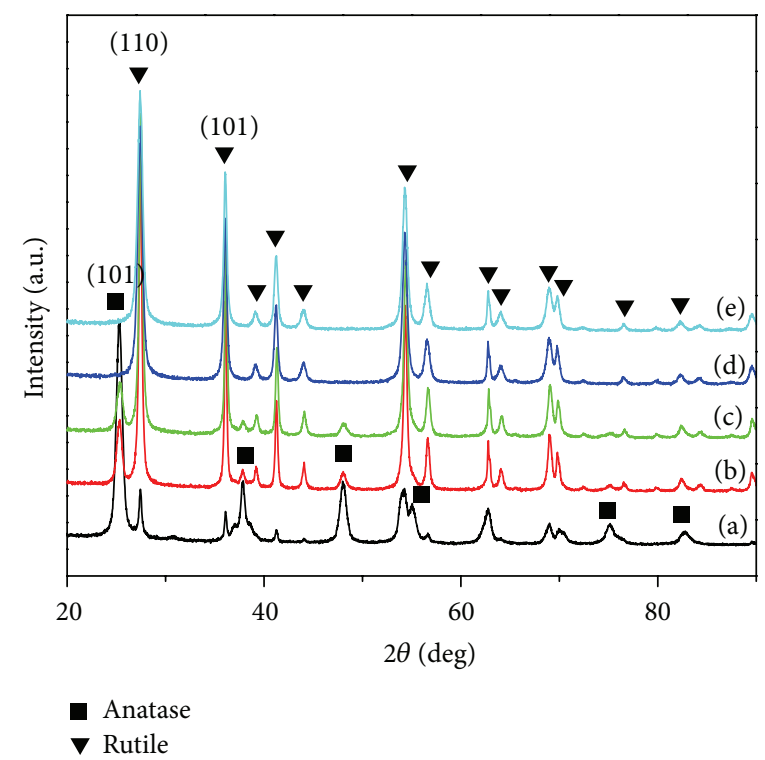

FIGURE 1: XRD patterns of $\mathrm{TiO}_{2}$ samples prepared with different Sn doping ratios: (a) $0 \%$, (b) $0.25 \%$, (c) $0.50 \%$, (d) $0.75 \%$, and (e) $1.00 \%$.

$100 \mathrm{~mL}$ autoclave and heated at $200^{\circ} \mathrm{C}$ for $12 \mathrm{~h}$. For Sn doped samples, appropriate volume of tin tetrachloride was added to distilled water in advance (the feed molar ratios of $\mathrm{Sn} / \mathrm{Ti}$ were modulated as $0.25 / 100,0.5 / 100,0.75 / 100$, and $1.0 / 100$, resp.).

The powder XRD experiments were performed on Bruker D8 Advance X-ray diffractometer using monochromic $\mathrm{Cu}$ $\mathrm{K} \alpha$ radiation $(\lambda=0.15418 \mathrm{~nm})$. The scanning electron microscopy (SEM) images were recorded using S4700 Hitachi Ltd. The transmission electron microscopy (TEM) was performed with a Tecnai G2 20 transmission electron microscope of HongKong Co., Ltd. The X-ray photoelectron spectroscopy (XPS) experiments were carried out on Thermo ESCALAB 250 and the binding energies are calibrated by $\mathrm{C} 1 s$ photoelectron peak $(284.6 \mathrm{eV})$.

\section{Results and Discussion}

The X-ray diffraction patterns of $\mathrm{TiO}_{2}$ samples with different Sn doping ratios are shown in Figure 1. It can be seen that the undoped $\mathrm{TiO}_{2}$ is mainly composed of anatase and weak diffraction peaks of rutile $\mathrm{TiO}_{2}$ can also be found in the XRD pattern. With the addition of $\mathrm{Sn}$, the samples undergo "reutilization" to give rutile as the predominant polymorph, and the conversion from anatase to rutile is completed on $0.75 \%$ and $1.0 \%$ Sn doped samples, which suggests that the doped $\mathrm{Sn}$ ions can promote the formation of rutile.

The TEM results in Figure 2 show that the particle shape changed from sphere (diameter of 10-20 nm) to rod (width of $\sim 20 \mathrm{~nm}$ and length of 100-200 nm) by Sn doping, which are consistent with SEM results (not shown here). The space between the lattice planes of $\mathrm{Sn}$-free $\mathrm{TiO}_{2}$ (Figure 2(a)) is $0.35 \mathrm{~nm}$, which corresponds well to the $d$ value of (101) plane for anatase. The lattice space of $0.33 \mathrm{~nm}$ displayed in Sn$\mathrm{TiO}_{2}$ samples (Figures 2(b)-2(e)) is equal to the $d$ value of
(110) plane for rutile. Therefore, it is reasonable to conclude that the $\mathrm{Sn}$-free $\mathrm{TiO}_{2}$ spherical nanocrystals are mainly anatase structure and the $\mathrm{Sn}$ doped $\mathrm{TiO}_{2}$ rod-like particles are rutile. As for our samples, with an increasing of Sn doping amount in $\mathrm{TiO}_{2}$, the content of the spherical anatase decreases and the rod-like rutile increases, illustrating that Sn doping facilitates the phase conversion from anatase to rutile, which is consistent with XRD. Furthermore, the HRTEM images reveal rod-like building units and nanocrystal growth along the [110] axis, indicating that the formation of the rod-like $\mathrm{TiO}_{2}$ is the result of the preferential growth (PG) in crystallographic orientation favored by $\mathrm{Sn}$ incorporation. Since Ti (IV) and Sn (IV) ions have the similar ionic radii, it is reasonable to deduce that $\mathrm{Sn}$ ions substitute lattice $\mathrm{Ti}$, which is confirmed by our subsequent experiment. The EDX spectrum in Figure 2(e) also confirms the existence of $\mathrm{Sn}$ in $\mathrm{TiO}_{2}$ nanocrystals.

Figure 3 shows the XPS spectra of $\mathrm{Sn}$ doped $\mathrm{TiO}_{2}$ sample with $\mathrm{Sn} / \mathrm{Ti}$ atomic ratio of $1 \%$. As for Ti $2 p_{3 / 2}$ spectrum in Figure 3(a), the two peaks at $458.1 \mathrm{eV}$ and $458.7 \mathrm{eV}$ could be assigned to $\mathrm{O}-\mathrm{Ti}-\mathrm{O}$ and $\mathrm{Ti}-\mathrm{O}-\mathrm{Sn}$, respectively. Due to the electronegativity of $\mathrm{Sn}$ (1.96) which is larger than $\mathrm{Ti}$ (1.54) [20], the substitution of Sn for Ti in the lattice leads to the shift of binding energy to a higher value.

As for O1s spectrum in Figure 3(b), the peak at $532.2 \mathrm{eV}$ is attributed to surface hydroxyl oxygen atoms. The peak at $529.3 \mathrm{eV}$ is the binding energy of $\mathrm{O} 1 \mathrm{~s}$ in $\mathrm{Ti}-\mathrm{O}-\mathrm{Ti}$, while the occurrence of the peak at $530 \mathrm{eV}$ is the result of Sn substitute for $\mathrm{Ti}$ leading to the positive shift. These observations all confirm the formation of Ti-O-Sn structure in the Sn doped $\mathrm{TiO}_{2}$, owing to the substitution of Ti by $\mathrm{Sn}$.

As shown in Figure 4, both anatase and rutile phase coexist at short treatment time, and the ratio of rutile/anatase increases with treatment time prolonging. A similar finding was reported by Zhang and Gao [21] who stated that 


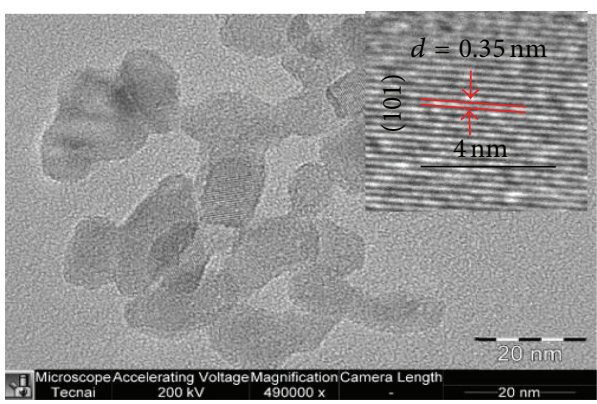

(a)

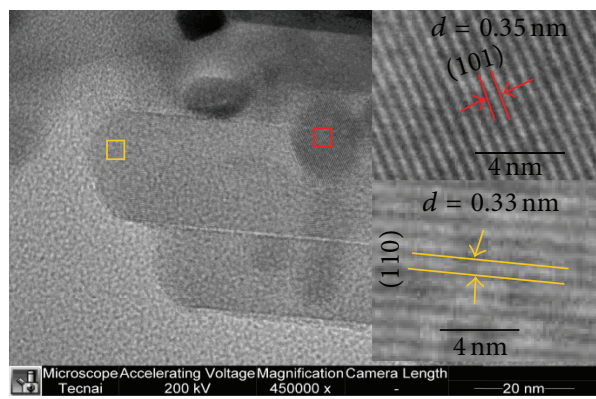

(c)

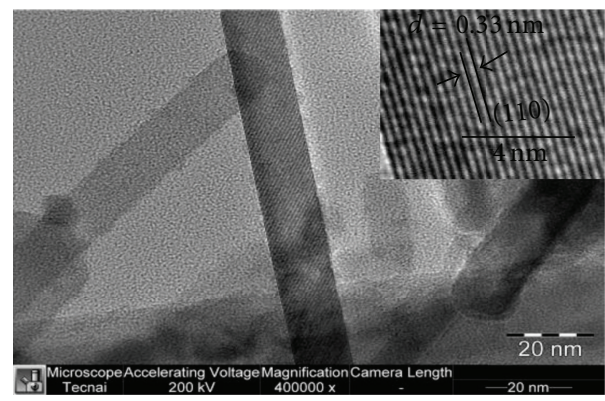

(e)

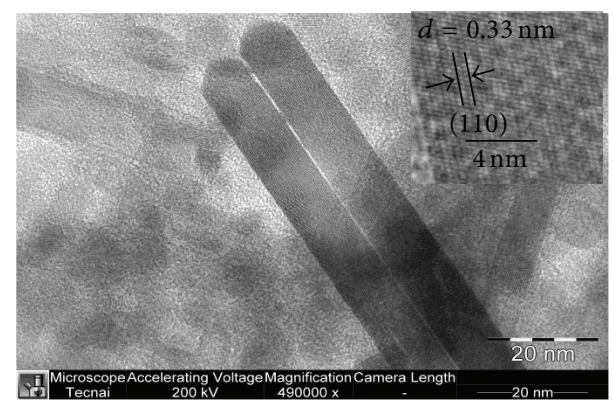

(b)

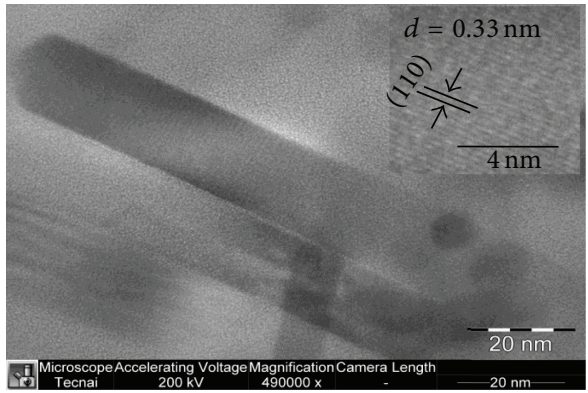

(d)

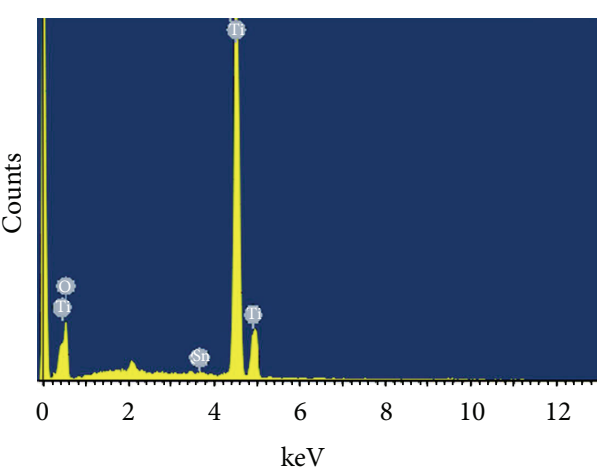

(f)

FIGURE 2: TEM images of $\mathrm{TiO}_{2}$ samples prepared with different Sn doping ratios: (a) $0 \%$, (b) $0.25 \%$, (c) $0.50 \%$, (d) $0.75 \%$, (e) $1.00 \%$, and (f) EDX spectrum of $1 \% \mathrm{Sn}$ doped $\mathrm{TiO}_{2}$ nanocrystals.

phase transformation occurred simultaneously with particle growth.

It has been shown that the oxygen vacancies of $\mathrm{TiO}_{2}$ increase if foreign cations replace $\mathrm{Ti}^{4+}$ ions [22]. Vemury and Pratsinis [23] found that the formation of rutile phase was enhanced either by introducing dopant oxides with the same crystal structure as rutile or by creating oxygen vacancies by doping cations. It has been reported that the rutile fraction increases at a higher $\mathrm{Eu}^{3+}$ addition owing to the creation of oxygen vacancies by replacing the $\mathrm{Ti}^{4+}$ sites with subvalent $\mathrm{Eu}^{3+}$ ions in the $\mathrm{TiO}_{2}$ [24]. In our samples, the creation of oxygen vacancies is by replacing the $\mathrm{Ti}^{4+}$ sites with $\mathrm{Sn}^{4+}$ ions in $\mathrm{TiO}_{2}$ and therefore the rutile formation can be enhanced. Moreover, it was supposed that there is a relationship between the phase transformation and the nanocrystal growth process [25] and the preferential growth process aids phase transformation. The minimization of the area of high-energy surface faces promoted by the preferential growth process may be an extra driving force for the phase transformation from anatase to rutile phase.

\section{Conclusions}

In summary, the promoting roles of $\mathrm{Sn}^{4+}$ in both $\mathrm{TiO}_{2}$ phase transformation and morphology change have been confirmed in our study. The result demonstrated that morphology transition was related to the preferential growth process and the phase transformation was related to the creation of oxygen vacancies caused by Sn. Our observations of preferential growth coupled with phase transformation 


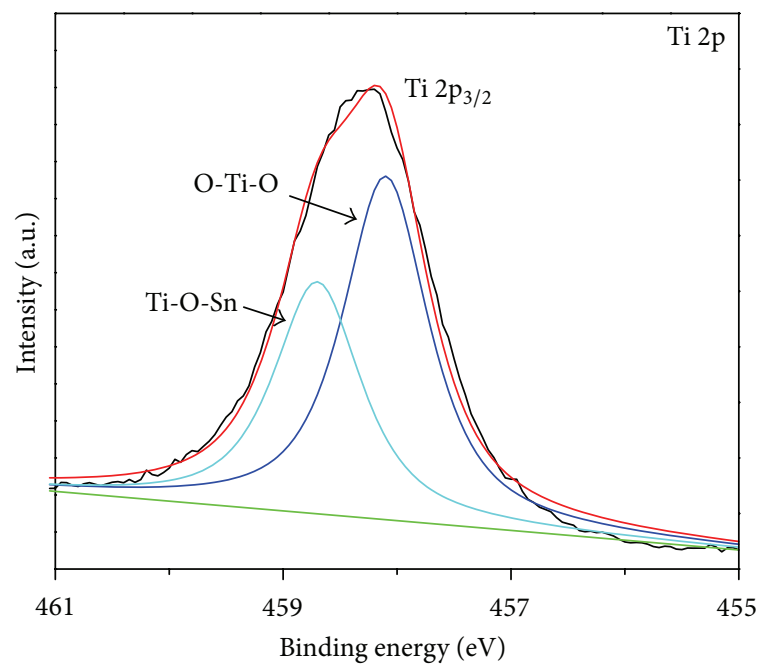

(a)

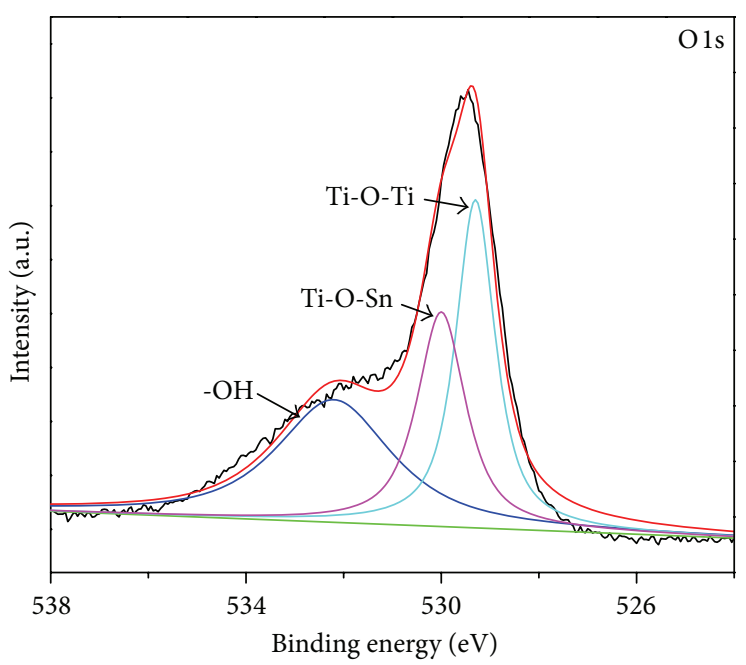

(b)

FIGURE 3: XPS spectra of the $1 \% \mathrm{Sn}$ doped $\mathrm{TiO}_{2}$ nanocrystals.

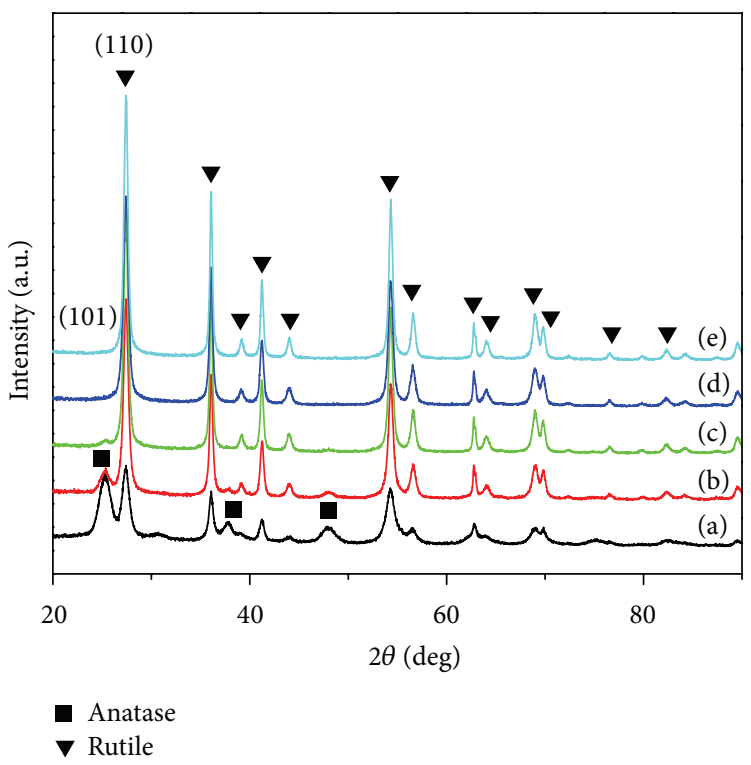

FIgURE 4: XRD patterns of the 1\% Sn doped samples with different times: (a) $3 \mathrm{~h}$, (b) $6 \mathrm{~h}$, (c) $9 \mathrm{~h}$, (d) $12 \mathrm{~h}$, and (e) $15 \mathrm{~h}$.

process led us to understand the preferential growth process aided phase transformation.

\section{Conflict of Interests}

The authors declare that there is no conflict of interests regarding the publication of this paper.

\section{Acknowledgments}

This work was supported by Beijing Key Laboratory of Bioprocess, State Key Laboratory of Chemical Resource Engineering, China 863 Project (nos. 2009AA03Z802 and
2009AA03Z803), and Amoy Major Scientific and Technological Innovation Project (2012S0305).

\section{References}

[1] S. W. Cao, X. F. Liu, Y. P. Yuan et al., "Artificial photosynthetic hydrogen evolution over g- $\mathrm{C}_{3} \mathrm{~N}_{4}$ nanosheets coupled with cobaloxime," Physical Chemistry Chemical Physics, vol. 15, no. 42, pp. 18363-18366, 2013.

[2] P. Hu, S. S. Pramana, S. W. Cao et al., "Ion-induced synthesis of uniform single-crystalline sulphide-based quaternary-alloy hexagonal nanorings for highly efficient photocatalytic Hydrogen evolution," Advanced Materials, vol. 25, no. 18, pp. 25672572, 2013. 
[3] S. W. Cao, Y. P. Yuan, J. Fang et al., "In-situ growth of CdS quantum dots on $g-\mathrm{C}_{3} \mathrm{~N}_{4}$ nanosheets for highly efficient photocatalytic hydrogen generation under visible light irradiation," International Journal of Hydrogen Energy, vol. 38, pp. 1258-1266, 2013.

[4] M. S. Yao, P. Hu, Y. B. Cao, W. C. Xiang, X. Zhang, and F. L. Yuan, "Morphology-controlled $\mathrm{ZnO}$ spherical nanobelt-flower arrays and their sensing properties," Sensors and Actuators B: Chemical, vol. 177, pp. 562-569, 2013.

[5] S. W. Cao, J. Fang, M. M. Shahjamali et al., "In situ growth of Au nanoparticles on $\mathrm{Fe}_{2} \mathrm{O}_{3}$ nanocrystals for catalytic applications," CrystEngComm, vol. 14, pp. 7229-7235, 2012.

[6] A. Fujishima, T. N. Rao, and D. A. Tryk, "Titanium dioxide photocatalysis," Journal of Photochemistry and Photobiology C: Photochemistry Reviews, vol. 1, no. 1, pp. 1-21, 2000.

[7] W. X. Dai, X. Chen, X. P. Zheng et al., "Photocatalytic oxidation of $\mathrm{CO}$ on $\mathrm{TiO}_{2}$ : chemisorption of $\mathrm{O}_{2}, \mathrm{CO}$, and $\mathrm{H}_{2}$," ChemPhysChem, vol. 10, no. 2, pp. 411-419, 2009.

[8] M. S. Hassan, T. Amna, O. B. Yang, H. C. Kim, and M. S. Khil, " $\mathrm{TiO}_{2}$ nanofibers doped with rare earth elements and their photocatalytic activity," Ceramics International, vol. 38, pp. 5925-5930, 2012.

[9] Y. X. Li, S. Q. Peng, F. Y. Jiang, G. X. Lu, and S. B. Li, "Effect of doping $\mathrm{TiO}_{2}$ with alkaline-earth metal ions on its photocatalytic activity," Journal of the Serbian Chemical Society, vol. 72, no. 4, pp. 393-402, 2007.

[10] P. Z. Si, W. Jiang, H. X. Wang et al., "Large scale synthesis of nitrogen doped $\mathrm{TiO}_{2}$ nanoparticles by reactive plasma," Materials Letters, vol. 68, pp. 161-163, 2012.

[11] G. S. Wu, J. L. Wen, J. P. Wang, D. F. Thomas, and A. C. Chen, "A facile approach to synthesize $\mathrm{N}$ and $\mathrm{B}$ co-doped $\mathrm{TiO}_{2}$ nanomaterials with superior visible-light response," Materials Letters, vol. 64, pp. 1728-1731, 2010.

[12] V. D. Binas, K. Sambani, T. Maggos, A. Katsanaki, and G. Kiriakidis, "Synthesis and photocatalytic activity of Mn-doped $\mathrm{TiO}_{2}$ nanostructured powders under UV and visible light," Applied Catalysis B: Environmental, vol. 113-114, pp. 79-86, 2012.

[13] H. J. Liu, G. G. Liu, and Q. X. Zhou, "Preparation and characterization of $\mathrm{Zr}$ doped $\mathrm{TiO}_{2}$ nanotube arrays on the titanium sheet and their enhanced photocatalytic activity," Journal of Solid State Chemistry, vol. 182, no. 12, pp. 3238-3242, 2009.

[14] L. Sikong, B. Kongreong, D. Kantachote, and W. Sutthisripok, "Photocatalytic activity and antibacterial behavior of $\mathrm{Fe}^{3+}$ doped $\mathrm{TiO}_{2} / \mathrm{SnO}_{2}$ nanoparticles," Energy Research Journal, vol. 1, no. 2, pp. 120-125, 2010.

[15] J.-Y. Park, J.-J. Yun, C.-H. Hwang, and I.-H. Lee, "Influence of silver doping on the phase transformation and crystallite growth of electrospun $\mathrm{TiO}_{2}$ nanofibers," Materials Letters, vol. 64, no. 24, pp. 2692-2695, 2010.

[16] J. P. Xu, Y. B. Lin, Z. H. Lu et al., "Enhanced ferromagnetism in Mn-doped $\mathrm{TiO}_{2}$ films during the structural phase transition," Solid State Communications, vol. 140, no. 11-12, pp. 514-518, 2006.

[17] T. H. Jun and K. S. Lee, "Cr-doped $\mathrm{TiO}_{2}$ thin films deposited by RF-sputtering," Materials Letters, vol. 64, no. 21, pp. 2287-2289, 2010.

[18] Y.-H. Zhang and A. Reller, "Phase transformation and grain growth of doped nanosized titania," Materials Science and Engineering C, vol. 19, no. 1-2, pp. 323-326, 2002.

[19] Y. Q. Cao, T. He, L. S. Zhao, E. J. Wang, W. S. Yang, and Y. A. Cao, "Structure and phase transition behavior of $\mathrm{Sn}^{4+}$-doped $\mathrm{TiO}_{2}$ nanoparticles," Journal of Physical Chemistry C, vol. 113, no. 42, pp. 18121-18124, 2009.

[20] J. Li and C. Z. Hua, "Hollowing Sn-doped $\mathrm{TiO}_{2}$ nanospheres via Ostwald ripening," Journal of the American Chemical Society, vol. 129, no. 51, pp. 15839-15847, 2007.

[21] Q. Zhang and L. Gao, "Preparation of oxide nanocrystals with tunable morphologies by the moderate hydrothermal method: insights from rutile $\mathrm{TiO}_{2}$," Langmuir, vol. 19, no. 3, pp. 967-971, 2003.

[22] R. Arroyo, G. Córroyo, J. Padilla, and V. H. Lara, "Influence of manganese ions on the anatase-rutile phase transition of $\mathrm{TiO}_{2}$ prepared by the sol-gel process," Materials Letters, vol. 54, pp. 397-402, 2002.

[23] S. Vemury and S. E. Pratsinis, "Dopants in flame synthesis of titania," Journal of the American Ceramic Society, vol. 78, no. 11, pp. 2984-2992, 1995.

[24] J. G. Li, X. H. Wang, K. J. Watanabe, and T. M. Ishigaki, "Phase structure and luminescence properties of $\mathrm{Eu}^{3+}$-doped $\mathrm{TiO}_{2}$ nanocrystals synthesized by $\mathrm{Ar} / \mathrm{O}_{2}$ radio frequency thermal plasma oxidation of liquid precursor mists," The Journal of Physical Chemistry B, vol. 110, no. 3, pp. 1121-1127, 2006.

[25] C. Ribeiro, C. Vila, D. B. Stroppa et al., "Anisotropic growth of oxide nanocrystals: insights into the rutile $\mathrm{TiO}_{2}$ phase," Journal of Physical Chemistry C, vol. 111, no. 16, pp. 5871-5875, 2007. 

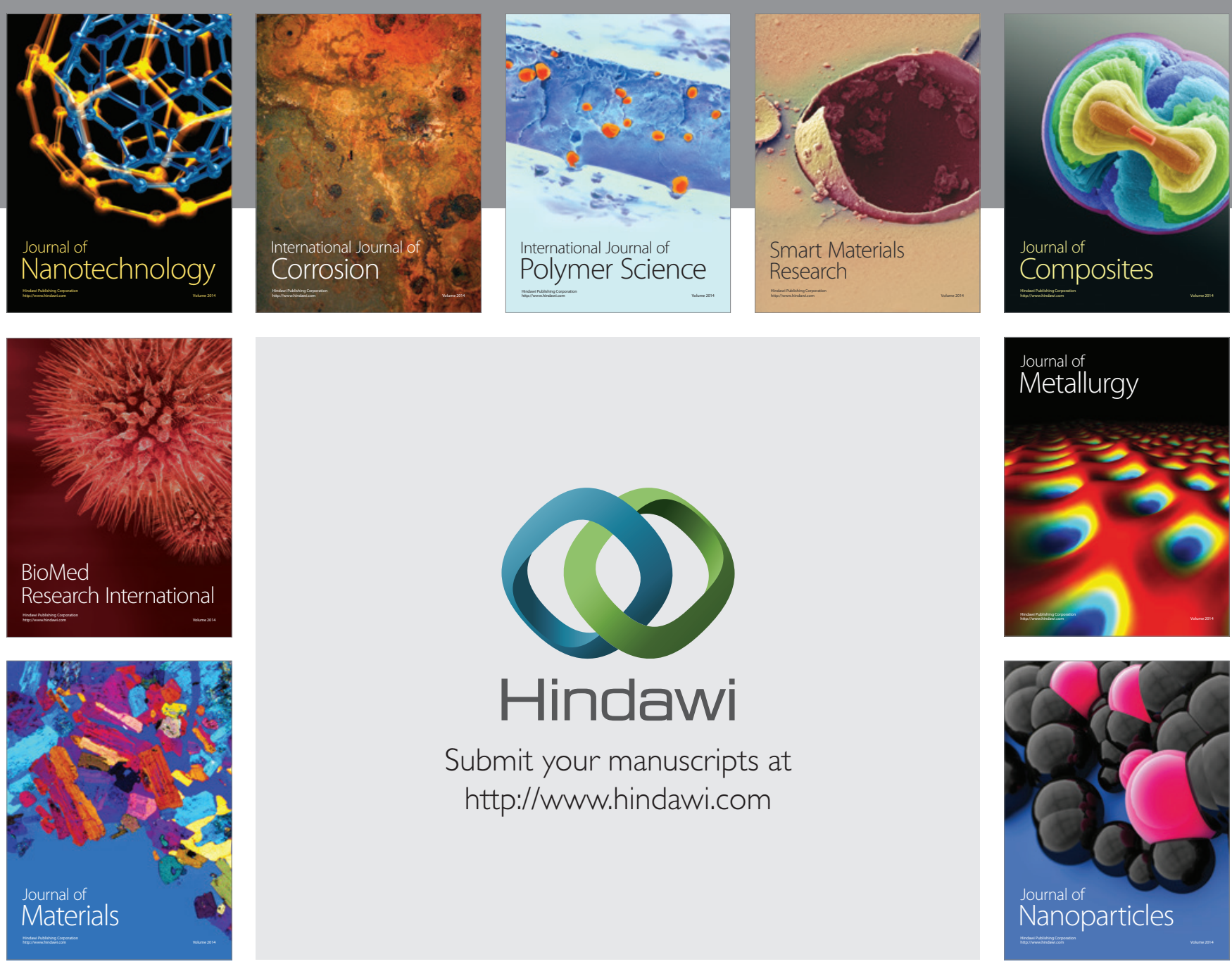

Submit your manuscripts at http://www.hindawi.com
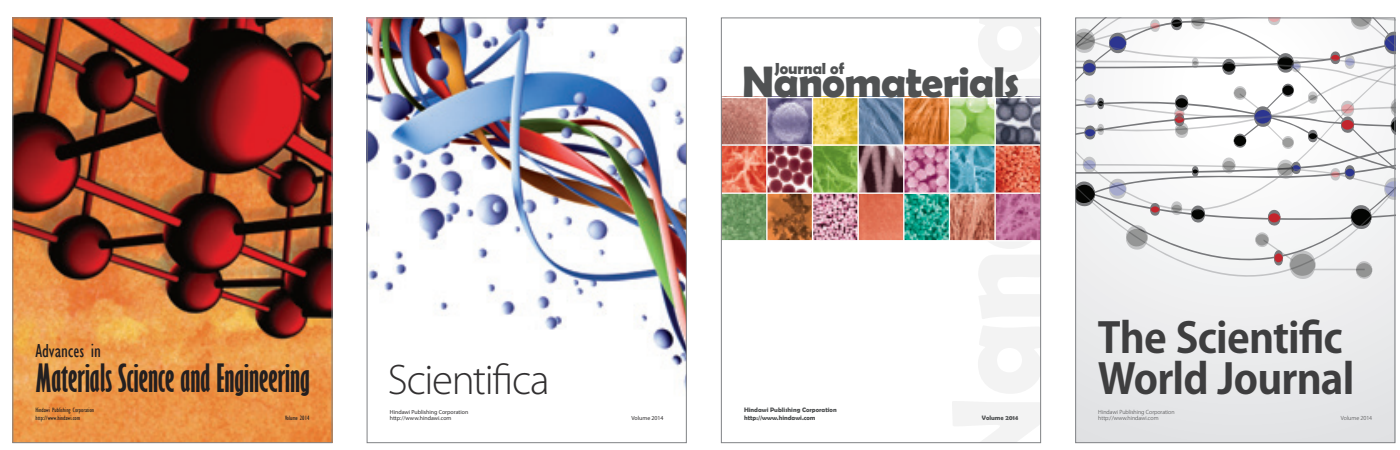

\section{The Scientific World Journal}
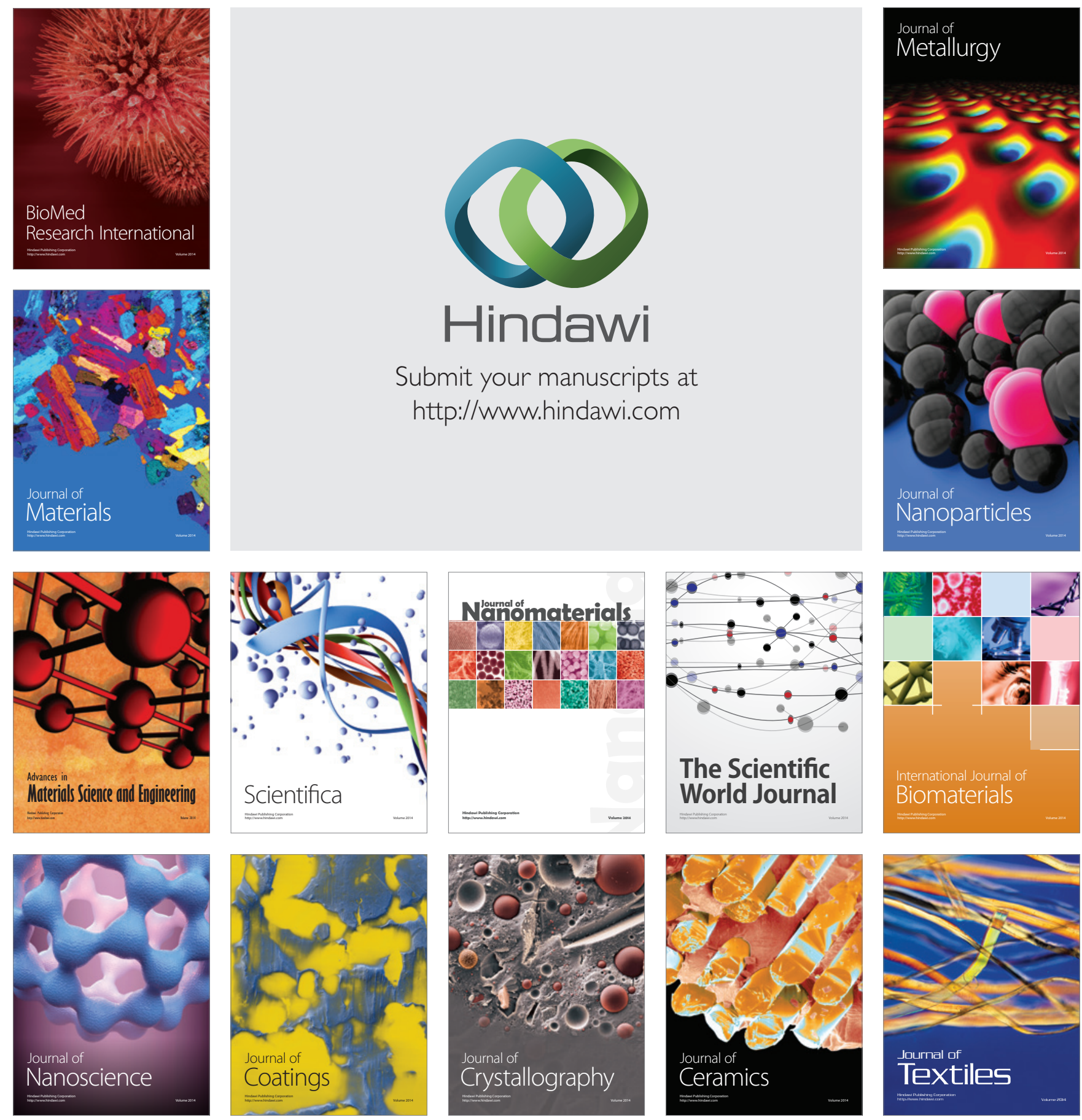